\title{
POLA PENGGUNAAN REMITAN DI NAGARI LAGAN MUDIK PUNGGASAN KECAMATAN LINGGO SARI BAGANTI KABUPATEN PESISIR SELATAN
}

\author{
Novira Esa Framujiastri ${ }^{1}$, Rery Novio ${ }^{2}$ \\ Program Studi Pendidikan Geografi \\ Fakultas Ilmu Sosial, Universitas Negeri Padang \\ Email noviraesa96@yahoo.co.id
}

\begin{abstract}
Abstrak
Penelitian ini bertujuan untuk mengetahui pola penggunaan remitan dan dampak remitan terhadap sosial ekonomi rumah tangga di Nagari Lagan Mudik Punggasan. Penelitian ini tergolong deskriptif dengan pendekatan kuantitatif. Populasi penelitian merupakan seluruh keluarga migran. Sampel diperoleh sebanyak 57 responden menggunakan pendekatan Isac Michel. Teknik penarikan sampel yang digunakan yaitu sampel acak sederhana. Hasil penelitian menemukan: (1) pola penggunaan remitan di Nagari Lagan Mudik Punggasan lebih banyak digunakan untuk kebutuhan konsumtif dengan persentase 59,42\%. Bentuk penggunaan paling banyak yaitu untuk membayar tagihan listrik dan air, bahan sembako, serta membeli peralatan elektronik. (2) dampak remitan terhadap sosial ekonomi rumah tangga sebesar 20\% yang termasuk kategori mendekati tidak berdampak.
\end{abstract}

Kata Kunci: Remitan, Pola Penggunaan Remitan, Dampak Remitan

\section{Abstract}

The aims of this paper is to find out the pattern of remittance usage and the impact of remittances on household socio-economics in Lagan Mudik Punggasan. The type of this study is quantitative descriptive. The population is all migrant families. Used the Isac Michel approach, the sample get for 57 respondents. The sampling technique used simple random sampling. This paper find out: (1) the pattern of remittance usage in Lagan Mudik Punggasan more used for consumptive needs with a percentage of $59.42 \%$. Mostly use are to pay for electricity and water bills, groceries, and buy electronic equipment. (2) the impact of remittances on household socio-economics is $20 \%$ classified as approaching has no impact.

Keywords: Remittance, Pattern of Remittance Usage, Impact of Remittance

\footnotetext{
${ }^{1}$ Mahasiswa Program Studi Pendidikan Geografi

${ }^{2}$ Dosen Jurusan Geografi Fakultas Ilmu Sosial Universitas Negeri Padang
} 


\section{PENDAHULUAN}

Peningkatan jumlah penduduk di suatu wilayah akan berakibat terhadap kehidupan sosial ekonomi masyarakat daerah yang bersangkutan. Berkembangnya kehidupan sosial ekonomi juga tercermin dari meningkatnya mobilitas penduduk. Dalam hal ini, beberapa penduduk memilih bermobilitas ke luar daerah untuk mendapatkan kesempatan kerja yang lebih layak dan mampu menunjang kehidupan pribadi dan juga keluarganya. Bentuk mobilitas yang terjadi kebanyakan adalah dari perdesaan ke perkotaan.

Daerah perkotaan dianggap sebagai pusat pembangunan yang menyediakan berbagai alternatif pilihan pekerjaan. Disamping itu, kota juga diyakini sebagai tempat berkembangnya ilmu pengetahuan dan teknologi, serta ide dan kreativitas masyarakat. Kota juga dilengkapi berbagai sarana dan prasarana, serta merupakan tempat berpadunya berbagai kebudayaan. Inilah yang menjadi daya tarik tersendiri, sehingga cukup banyak masyarakat yang lebih memilih untuk tinggal dan menetap di kota daripada di desa.

Etnis Minangkabau merupakan salah satu etnis di Indonesia yang memiliki tingkat mobilitas yang tinggi. Hampir diseluruh kota di Indonesia terdapat etnis Minangkabau. Mobilitas yang tinggi tersebut dipengaruhi oleh adanya tradisi merantau pada etnis Minangkabau. Di Minangkabau, laki-laki yang sudah cukup umur, akan pergi keluar daerah untuk merantau. Mereka merantau dengan harapan yang tinggi untuk membawa hasil dari rantau ke kampung halaman. Masyarakat Minangkabau sejak dahulu juga tumbuh dengan arif menyikapi lingkungan disekitar mereka (Novio, 2016).

Merantau dapat diartikan sebagai sebuah pola migrasi masyarakat Minangkabau ke suatu wilayah atau daerah yang menjanjikan harapan untuk masa depan dan pengembangan diri, dalam upaya mencapai kehidupan sosial ekonomi yang lebih baik Naim (1984). Perantau Minangkabau ada yang berhasil dan ada pula yang kurang berhasil. Tetapi setidaknya jarang dari mereka yang kurang berhasil terus pulang ke kampung halaman. Mereka akan menunggu bekalnya cukup dulu untuk pulang, atau jika tidak pulang mereka akan mengirimkan uang untuk memenuhi kebutuhan keluarga dan sanak saudaranya. Secara tidak langsung, mereka ingin meningkatkan taraf hidup keluarga yang ada di kampung halaman. Kemudian dalam perkembangannya, penduduk yang merantau ini dapat mengirimkan remitan ke daerah asal.

Barclay (1984) mengemukakan bahwa pada mulanya istilah remitan (remittance) adalah uang atau barang yang dikirim oleh migran ke daerah asal, sementara migran masih berada di tempat tujuan. Dalam perkembangannya kemudian definisi ini mengalami perluasan, tidak hanya uang dan barang, tetapi keterampilan dan ide juga digolongkan remitan bagi daerah asal. 
Berdasarkan pengertian remitan di atas, maka seharusnya remitan memberikan dampak positif terhadap kehidupan sosial maupun ekonomi masyarakat desa. Dari segi ekonomi keberadaan remitan sangatlah penting karena mampu meningkatkan ekonomi keluarga dan juga untuk kemajuan bagi masyarakat penerimanya. Di samping sebagai salah satu instrumen perubahan ekonomi, remitan juga mempunyai dampak yang luas dalam kehidupan sosial maupun budaya bagi keluarga, masyarakat penerima dan daerah asalnya.

Lagan Mudik Punggasan merupakan suatu nagari yang terletak Kecamatan Linggo Sari Baganti, Kabupaten Pesisir Selatan. Berdasarkan data BPS (Kecamatan Linggo Sari Baganti dalam Angka tahun 2018), KK pada nagari ini berjumlah 500 dengan jumlah penduduk 2167 jiwa, sebanyak 970 penduduk menggantungkan perekonomiannya pada sektor pertanian dengan komoditas utama adalah karet, padi, dan jagung. Lagan Mudik Punggasan dengan luas wilayah 25,60 $\mathrm{Km}^{2}$, sedangkan luas lahan pertaniannya sebanyak $12,15 \mathrm{Km}^{2}$ atau $47 \%$ dari keseluruhan wilayah seharusnya berpotensi untuk mendongkrak ekonomi masyarakat. Namun pada kenyatannya, sektor pertanian tidak dapat terlalu diandalkan. Salah satu langkah yang diambil sebagian masyarakat Lagan Mudik Punggasan adalah meninggalkan kampung halaman (merantau) demi mendapatkan pekerjaan yang lebih layak, kemudian mereka yang merantau dapat membantu kehidupan keluarga yang ditinggalkan dengan mengirimkan remitan ke kampung halaman.

Remitan yang dikirimkan migran kepada keluarganya di kampung halaman dapat digunakan untuk berbagai macam keperluan baik secara konsumtif maupun produktif. Mustapita dan Rizal (2017) mengemukakan pendapatnya tentang pola penggunaan remitan, dimana pola penggunaan remitan konsumtif adalah penggunaan remitan yang langsung habis pakai dalam jangka waktu pendek. Penggunaan tersebut antara lain untuk: (a) renovasi rumah, (b) kebutuhan seharihari, (c) kendaraan, (d) barang elektronik, dan (e) membayar hutang. Sementara itu, pola penggunaan remitan produktif adalah penggunaan remitan yang dapat menghasilkan nilai tambah baik secara materil maupun non materil dalam jangka waktu panjang. Beberapa bentuk penggunaan remitan produktif diantaranya untuk: (a) membeli lahan, seperti tanah dan sawah, (b) hewan ternak, (c) modal usaha, (d) disumbangkan, serta (e) membiayai pendidikan anak.

Dalam penggunaan remitan di Nagari Lagan Mudik Punggasan masih ada kondisi sosial ekonomi keluarga migran yang tidak berubah sama sekali, padahal selalu menerima kiriman remitan setiap bulannya. Bertolak dari latar belakang dan permasalahan di atas, maka penulis tertarik untuk meneliti tentang pola penggunaan remitan di Nagari Lagan Mudik Punggasan, Kecamatan Linggo Sari Baganti, Kabupaten Pesisir Selatan. 


\section{METODE PENELITIAN}

Penelitian ini tergolong penelitian deskriptif dengan pendekatan kuantitatif. Penelitian deskriptif dengan pendekatan kuantitatif dalam penelitian ini dimaksudkan untuk mendapatkan gambaran dan keterangan mengenai pola penggunaan remitan di Nagari Lagan Mudik Punggasan, Kecamatan Linggo Sari Baganti, Kabupaten Pesisir Selatan.

Populasi dalam penelitian ini adalah seluruh keluarga migran di Nagari Lagan Mudik Punggasan. Migran yang berasal dari Nagari Lagan Mudik Punggasan tersebar di beberapa wilayah baik di dalam maupun di luar Provinsi Sumatera Barat. Pada penelitian ini keluarga migran di Nagari Lagan Mudik Punggasan tidak diketahui jumlahnya dengan pasti, sehingga untuk menghitung sampel minimum yang dibutuhkan adalah dengan pendekatan Isac Michel (Siregar, 2015) untuk jumlah populasi yang tidak diketahui. Berdasarkan pendekatan tersebut didapatkan jumlah sampel sebanyak 57 orang. Teknik penarikan sampel yang digunakan yaitu sampel acak sederhana (simple random sampling).

Sumber data yang digunakan dalam penelitian ini adalah data primer yang didapat dengan membagikan kuesioner kepada keluarga migran di Nagari Lagan Mudik Punggasan. Analisis data yang digunakan adalah teknik analisis statistik, yaitu statistik deskriptif dengan perhitungan persentase. Untuk mengukur dampak remitan terhadap sosial ekonomi rumah tangga, peneliti menggunakan
Skala Guttman model cross sectional (tradisional).

\section{HASIL DAN PEMBAHASAN}

Penelitian dilaksanakan di Nagari Lagan Mudik Punggasan, Kecamatan Linggo Sari Baganti, Kabupaten Pesisir Selatan. Peta lokasi penelitian disajikan pada Gambar 1.

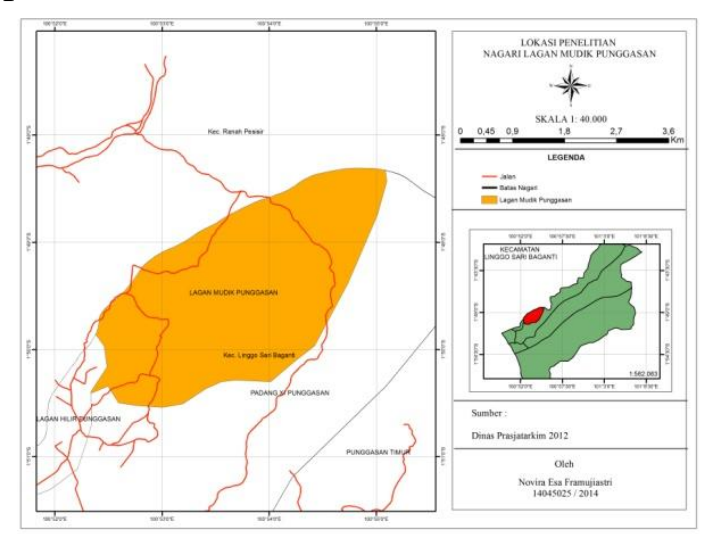

Gambar 1. Peta Lokasi Penelitian

Hasil penelitian ini akan memberikan gambaran dan keterangan mengenai pola penggunaan remitan di Nagari Lagan Mudik Punggasan, Kecamatan Linggo Sari Baganti, Kabupaten Pesisir Selatan. Hasil penelitian menemukan: (1) pola penggunaan remitan lebih banyak digunakan pada kegiatan konsumtif. Hal ini sejalan dengan pendapat Wulan dalam Dibyantoro dan Alie (2014) bahwa penggunaan remitan digolongkan konsumtif apabila alokasi remitan tidak dapat memperbesar output atau keluaran dan penghasilan di kemudian hari. Dimana penggunaan remitan langsung habis pakai dalam jangka waktu pendek. Bentuk penggunaan remitan paling banyak yang dilakukan keluarga migran 
di Nagari Lagan Mudik Punggasan antara lain untuk membayar tagihan listrik dan air, bahan sembako, serta membeli peralatan elektronik. (2) dampak remitan terhadap sosial ekonomi rumah tangga di Nagari Lagan Mudik Punggasan sebesar 20\%. Dilihat dari teori yang ada, Mahmud, et al (2015) menyebutkan remittances can lead to economic growth simply by increasing the migrant's household income, regardless of whether this additional income is spent on consumption or savings (remitan dapat meningkatkan pertumbuhan ekonomi dengan bertambahnya pendapatan rumah tangga migran, baik digunakan untuk konsumsi maupun ditabung). Akan tetapi, dampak remitan sebesar $20 \%$ (dalam nominal 0,2) pada interpretasi terhadap nilai X dalam pengukuran Skala Guttman termasuk kategori mendekati tidak berdampak (Kasim, 2015).

\section{PENUTUP}

\section{Simpulan}

Pola penggunaan remitan di Nagari Lagan Mudik Punggasan, Kecamatan Linggo Sari Baganti, Kabupaten Pesisir Selatan lebih banyak digunakan untuk kebutuhan konsumtif dengan persentase $59,42 \%$. Bentuk penggunaan remitan konsumtif paling banyak yaitu untuk membayar tagihan listrik dan air, bahan sembako, serta membeli peralatan elektronik. Dampak remitan terhadap sosial ekonomi rumah tangga di Nagari Lagan Mudik Punggasan, Kecamatan Linggo Sari Baganti, Kabupaten Pesisir
Selatan sebesar 20\% yang termasuk kategori mendekati tidak berdampak.

\section{Saran}

Berdasarkan kesimpulan diatas maka peneliti menyarankan: (1) keluarga migran sebaiknya diberikan pelatihan oleh pemerintah daerah terkait penggunaan remitan yang bermanfaat dan bersifat produktif. (2) remitan yang dikirimkan diharapkan mampu meningkatkan kondisi sosial ekonomi melalui pemanfaatan secara arif dan bijaksana agar memiliki dampak positif dalam kehidupan sehari-hari.

\section{DAFTAR PUSTAKA}

Abdul Latif Mahmud, et al. 2015. "Dynamics of Remittance in Bangladesh: A Case Study on United Commercial Bank (UCB).' Global Journals Inc. (USA). Hlm. 8-16.

Barclay, George W. 1984. Teknik Analisa Kependudukan. Jakarta: Bina Aksara.

BPS. 2018. Kecamatan Linggo Sari Baganti dalam Angka. Painan: BPS.

Dibyantoro, Bayu dan Muhammad Mukti Alie. 2014. "Pola Penggunaan Remitan Tenaga Kerja Indonesia (TKI) serta Pengaruhnya terhadap Perkembangan Daerah Asal." Jurnal UNDIP. HIm. 319-332.

Kasim, Iskani. 2015. Skala Guttman. Medan: Universitas Sumatera Utara.

Mustapita, Arini Fitria dan Mohammad Rizal. 2017. "Analisis Pola Penggunaan Remitan Migrasi 
Internasional secara Produktif dan Konsumtif di Kabupaten Malang." Jurnal UNISMA. HIm. 6-10.

Naim, Mochtar. 1984. Merantau Pola Migrasi Suku Minangkabau. Yogyakarta: Gadjah Mada University Press.

Novio, Rery. 2016. "Kearifan Arsitektur Rumah Gadang Minangkabau dalam Mitigasi Bencana." Jurnal Geografi. Hlm. 63-67.

Siregar, Syofian. 2015. Metode Penelitian Kuantitatif. Jakarta: Prenadamedia Group. 